\title{
De Bolivia A MÉXICo: VOcEs DE JÓVENES MUJEREs, SUS HISTORIAS Y SU IDENTIDAD
}

\author{
Gabriela Canedo-Vásquez \\ Verónica Ruiz-Lagier \\ María Andrés-Francisco
}

\section{Introducción}

E estas páginas las voces de dos jóvenes indígenas, una boliviana y otra guatemalteca que reside en Chiapas, nos llevarán por los caminos transitados de la identidad.

Gabriela Canedo Vásquez acompaña la experiencia vivida por una joven aymara boliviana, Mireya Pacosillo, quien hace una reflexión de lo que implica ser aymara en tiempos modernos y los cambios que se producen cuando se vive la identidad en un Estado reconocido como plurinacional. En el texto de Verónica Ruiz y María Andrés Francisco, las autoras nos relatan la vivencia de refugio en México de una joven guatemalteca. A través de las palabras de Mary, se puede observar el cambio cultural que se produjo en las comunidades de refugio, el esfuerzo que implicó para la siguiente generación obtener derechos ciudadanos, y la movilidad de quienes migran a Estados Unidos y regresan con nuevos valores a la comunidad.
Los temas de la identidad y del cambio cultural dentro de las comunidades, y cómo son vividos por los jóvenes y las mujeres en particular, en un contexto de modernización y globalización, son ámbitos apasionantes.

\section{La identidad aymara vivida como parte del corazón, como algo espiritual. Testimonio de una joven boliviana}

\section{Gabriela Canedo-Vásquez \\ Creo que es parte del corazón, de cómo vives tu identidad no porque lo diga, la gente te asume. Yo lo veo más espiritual, es una aceptación \\ Mireya Pacosillo}

Un martes cualquiera de junio me encontré con Mireya, como habíamos quedado, y nos fuimos a tomar un café para conversar. Mireya es una muchacha aymara de
Gabriela Canedo Vásquez. Profesora-investigadora en la Universidad Mayor de San Simón, Cochabamba, Bolivia. Correo electrónico: gcanedovasquez@yahoo.com.

Verónica Ruiz Lagier. Investigadora en la Dirección de Etnología y Antropología Social del Instituto Nacional de Antropología e Historia, México. Correo electrónico: veronicalagier@gmail.com.

María Andrés Francisco. Normalista. Correo electrónico: amorcito. virgo@hotmail.com.
Recibido: 2 de mayo de 2016. 
personalidad inquieta, curiosa y crítica, con una mirada política audaz, que comulga con el actual partido de gobierno, el Movimiento al Socialismo. Actualmente ha sido elegida asesora técnica de la Organización de Mujeres Bartolina Sisa, la asociación más grande de mujeres campesinas e indígenas en Bolivia y uno de los brazos fuertes del actual partido de gobierno. Estas razones me motivaron a conversar con ella para entender cómo los jóvenes viven su identidad, en especial en un contexto político donde la identidad indígena es enfatizada en el marco de un reciente Estado plurinacional.

\section{-Mireya, ite puedes presentar?}

- Mi nombre es Mireya Pacosillo. Tengo identidad aymara y tengo 32 años. He nacido en La Paz, pero el trabajo que he desarrollado ha ido reconstruyendo mi identidad. He ido viendo cuáles son las acciones que cada persona realiza, las reivindicaciones que los pueblos han ido desarrollando, y eso me ha permitido encontrarme, y al encontrarme he asumido mi propia identidad como mujer, pero además como una persona que representa a una cultura.

-Muybien, Mireya, iniciemos brevemente con la historia de tu familia. iTus papás o tus abuelos tienen vinculación conel campo?

- Mis papás también han nacido aquí. Mi abuelo es aymara y mi abuela es potosina. Mi abuelo hablaba aymara y mi abuela quechua, entonces, yo creo que por ahí tengo la necesidad de ver el tema de la identidad. Mi abuela es de pollera también.

-iHermanos?

-Uno solo.

- iEn qué barrio te has criado? ¿Cómo era tu vida de pequeña?

- He estudiado en el liceo Venezuela, un colegio de puras mujeres. Mi vida ha sido tranquila.

-Y de tu niñez iquérecuerdas?

- Ayudaba en la casa porque mis papás no tenían muchos recursos, entonces, yo tenía que ayudar en los quehaceres de la casa. Me dedicaba al estudio. Mi mamá hacía costura en la casa, pero se enfermó y estuvo dos años en el hospital; por eso, mi hermano y yo nos hemos criado con mis padrinos. Eso creo que me ha dado cierta madurez, yo creo. Mi papá tenía que trabajar, era chofer, tenía su auto, y tenía muchas cuentas que pagar. -Sales del bachillerato y iqué haces luego?

-Es irónico, porque mi mamá tenía la concepción de que la mujer tenía que ser de la casa, tenía que saber primero "aprender a ser buena mujer". Yo salí del colegio y la mayoría de mis compañeras entraron a la universidad y yo no, porque mi mamá dijo: "tú no sabes cocina, no sabes coser". Me puso en un instituto, Santa Rita, y ahí estudié un año sobre cocina y repostería, porque "tu esposo te va a waskear, pegar, si no sabes". Y tiene esa concepción aún, que tienes que ser de la casa y no puedes estar en la calle. Eso ha estado presente en mi vida.

— ¿Y desde cuándo inicias tu accionar político?

- Mi accionar político y de defensa de los derechos nació en el CEMSE. ${ }^{1}$ Pertenecía a un programa de jóvenes mujeres en el CEMSE, y ahí he ido reflexionando sobre cómo era la coyuntura actual, mi país, y cuáles eran los derechos de los jóvenes. He participado en las propuestas para la Asamblea Constituyente y he ido como representante de comisión para ver cómo trabajar la participación de los jóvenes. Y creo que el aporte que hemos tenido participando en la comisión fue sobre cómo conformábamos la participación de los jóvenes y la participación de género, las mujeres por circunscripción y las suplentes. He participado en ese proceso y hemos hecho la construcción de la propuesta. Tenía en ese entonces 18 o 19 años, había salido de bachiller.

—Después de estudiar, iqué hiciste?

-Entré a trabajar a una empresa de leche Vigor, por ocho meses. He ahorrado dinero y le he dicho a mi mamá que ya tenía el dinero, y me he inscrito a la universidad, a Ciencias de la Educación, porque yo tengo el sueño de ser docente, pero también una docente calificada. Entonces me he inscrito y a partir de ese entonces he ido trabajando, 
estudiando y participando en muchos grupos de jóvenes. He estado en el grupo de lucha contra el tabaco y en grupos de liderazgo. Era movida, nunca en casa, todo lo que no quería mi mamá, yo lo era.

\section{—iTú trabajas y estudias?}

-Básicamente he terminado mi carrera trabajando. Claro que he tenido ayuda de mi madre en la alimentación y en servicios básicos. Siempre he vinculado esas dos acciones, estudiar y trabajar. Además de que soy la mayor y no hay muchos recursos en casa. Lo importante es conseguir mis sueños, las utopías, y hasta ahora sigo.

- ¿Y cuál es ese sueño como joven, Mireya?

-Me estoy especializando en derechos humanos y quiero postular para ser defensor del pueblo. Esa es mi meta, y sé que hay un camino pero voy a continuar. No hay peor lucha que la que no se hace, y voy a tratar de conseguir lo que quiero.

Luego de conocer a grandes rasgos la vida de Mireya, entramos propiamente a abordar la temática de la identidad con el fin de que nos ayude a desentrañar cómo la viven los jóvenes.

—iTú te identificas como aymara?

一Sí.

—iPor qué? ¿Qvé te hace aymara?

-Los orígenes de mi abuelo. Mis padres tienen sus tierras en el lago Titicaca cerca de Chajwuaya [Departamento de La Paz]. Mi abuelo heredó sus tierras a mis padres. Entonces, mi papá y sus hermanos tienen su propia parcela. Cada año vamos a hacer la cosecha y a hacer la siembra, y nos ayudan, y ayudamos también. Cosechamos harta papa. Este año no hemos hecho porque la tierra está descansando. Eso me autoidentifica. Cuando haces ese trabajo, asumes cierta identidad con las personas que te rodean, y yo y mis padres llegamos, y es como si estuviéramos ahí, en la comunidad. Se tiene que ir a las reuniones, se reúnen en El Alto y siguen haciendo sus reuniones para ver el tema de la tierra, para ver qué le falta a la comunidad. Dos veces me ha tocado salir con el alcalde para hacer gestiones ante la alcaldía y la gobernación.

- ¿Y qué elementos más hacen a la identidad?

-En este país ha habido muchas cosas a partir de la construcción del Estado plurinacional, por lo menos el concepto. Me gusta partir de la comunidad, acompañar. Y yo les decía que sí; como me veían joven, tenía que acompañar a las autoridades a hacer gestiones a la ciudad. Cuando los escucho, los entiendo. Y tienes que acompañar. Yo les he acompañado al parlamento y era bien irónico. Yo siempre me visto como de la ciudad, porque lo he asumido como parte de la cultura también. Y ellos venían con sus trajes típicos, y resulta que al frente del parlamento, con su aguayo bien grande, empezaban a cambiarse, se ponían gorrita, ternito, ${ }^{2}$ así hemos entrado al parlamento. Es uno de los momentos que ha chocado en mi vida, porque icómo ellos, teniendo su propia identidad, tenían que entrar a un espacio público que además era del Estado, al parlamento, y tenían que cambiarse? Y traían una compañera que, mientras cuidaba el atado afuera con toda la ropa típica, los otros hemos entrado al parlamento. Entonces, han sido esas cosas las que he ido cuestionado, y me han hecho sentir orgullosa de lo que representa la comunidad, mi raíz; siempre he estado y eso me marcaba. Luego de la Asamblea Constituyente ya no pasan estas cosas. Yo me acuerdo que, después de que entró Evo, la gente ha entrado al parlamento con sus látigos [elementos típicos de la comunidad] sin problemas, antes no había eso. En el subconsciente de las personas estaba que, si te veían como campesino, te iban a tratar mal, y si entrabas con ternito, te trataban bien. Me gusta participar en las reuniones, no mucho en las fiestas. A mi papá no le gusta participar en las reuniones, entonces a mí me decía, como era la hija mayor, "anda a la reunión si tú quieres". Y me gusta eso. En el colegio también he sido la que organizaba las cosas. Es parte, creo, de la dinámica; me gusta estar y ayudar. 
- Entonces, Mireya, ibastaría la relación con la comunidad para ser aymara? ¿O tener las dos identidades, aymara y una más que corresponda a la ciudad? ¿Cómo lo vives?

—Eso es un poco complicado porque te dicen "si tú eres aymara, entonces ipor qué no vistes con ropa típica?, pero no es cuestión de identidad. Los de la ciudad hemos adoptado esta manera de vestir, los jeans y la citadina, y es difícil retomar las cosas, pero yo lo veo como normal. Para mí el sentirme identificada es una cuestión cultural, de acciones y espiritual porque creo en todo lo que la Pachamama ${ }^{3}$ te puede dar, las energías. Entonces me siento bien. Yo no quiero vestir con ropa típica para sentirme o decirme aymara. Tampoco necesito negar en otro ámbito lo que soy. Me he movido en ambos lados. No he sentido intolerancia o discriminación. Siempre he sido respetuosa de las identidades de los otros, y he pedido respeto a cómo yo pensaba y a cómo yo me identificaba.

- En tu trabajo con los jóvenes indígenas del Movimiento al Socialismo Instrumento Políticopor la Soberaníade los Pueblos (MAS-IPSP), iqué veías? ¿Cómo manejaban las dos identidades?

- Yo he visto un sincretismo en lo que cada uno es. Los compañeros de El Alto, la mayoría son aymaras, migrantes, les gusta el hip hop, el reggaetón y se visten con ropas anchas, pero asumen el concepto de identidad, pues dicen "nos ch'allaremos", ${ }^{4}$ haremos una "milluchadita" ${ }^{5}$ para que nos vaya bien en la reunión, para que salga bien y no salgamos peleados. He visto muy a menudo asumir este tipo de cosas. En el Chapare, en Cochabamba, la mayoría de jóvenes son quechuas y he visto jóvenes con esto del mestizaje de lo urbano y lo rural, vestidos normales, con ropa ancha, jeans, como cualquier joven de la ciudad. A la hora de terminar la reunión, termina con una zapateadita [baile típico], con sus charanguitos [instrumento musical típico]. No llevan abarcas, ${ }^{6}$ pero bailan zapateadita. Cantan canciones en quechua y es común que en reuniones lleven sus guitarras y canten música propia del país. Y son jóvenes de entre 18 y 25 años.

- iFaltaría algún elemento para reconocerse como tal? ¿O basta decir yo soy aymara?

-Creo que es parte del corazón, de cómo vives tu identidad. No porque lo digas la gente te asume. Yo lo veo más espiritual, es una aceptación. Si entras a las comunidades, no tienes que vestir como ellos, pero hay que tener el corazón como ellos. De todo el trabajo que he realizado, el tema de la confianza es prioritario. Es como tú reflejas de corazón, y lo que puedes ser, lo honesto que puedes ser.

- Paraque unapersona con determinada identidad pueda ser reconocida como tal, ibasta autoafirmarse?

- Hay muchos compañeros que dicen ipor qué nos peleamos tanto? Hablan de la constitución y dicen ipor qué la Constitución Política del Estado nos ha dividido entre indígenas, originarios y campesinos si al final todos somos bolivianos? Y no se asume como un tema de identidad, no se asumen con cierta nacionalidad, y tienen ciertos rasgos que los identifican pero no se asumen como tales. Dentro de las organizaciones de Tierras Bajas he visto eso, no se asumen como chimán o leco; soy boliviana, soy paceña, se respeta eso, pero muchos miran lo que son para asumirse como parte de la ciudad. Los aymaras y quechuas son más politizados y asumen su identidad de manera más rápida.

De esta manera, Mireya nos acerca al entramado de la identidad indígena y al surgimiento constante de la cuestión nacional: ¿soy tacana?, ¿soy mojeño?, ¿o soy boliviano o boliviana? Para entender de manera más profunda esta identificación, indagamos sobre los jóvenes del actual partido de gobierno.

— ¿Cómo inicias tu acercamiento al MAS? ¿Qué trabajo has hecho?

- He participado en los encuentros de jóvenes para la Asamblea Constituyente, y ahí he conocido a los compañeros del MAS y de otros partidos. Y 
también, con una posición política clara que yo tenía, entonces ellos me invitaron al partido, si yo quería participar, y yo les dije que sí. Me invitaron a la Dirección Nacional y trabajé en la oficina que representaba a Evo Morales, y he tenido la oportunidad de trabajar de manera cercana con estas dos personas: Evo Morales y Álvaro García Linera [actuales presidente y vicepresidente]. Incluso antes de las elecciones, estábamos en el aeropuerto y yo le dije a Evo Morales: "yo creo que ya usted va a ser presidente". Y me dijo: "voy a ser el Evo". Es la vinculación con el tema de la Asamblea Constituyente lo que me acercó a los jóvenes del MAS, me invitaron. También me permitieron apoyar en la Asamblea Legislativa. De la nueva $\mathrm{CPE},{ }^{7} \mathrm{y}$ he profundizado en la Constitución, he ido a socializarla, pero además a coordinar con algunas organizaciones sociales. - Se maneja lo indígena como lo comunitario, como la panacea en la que no hay conflictos, y que lo occidental es individualista, más de corte citadino. ¿Cómoves túel hecho de que lo identitario se maneje como locolectivo, lo grupal? -Yo creo que es parte de la idealización de lo que es comunitario, complementario, pero en realidad no hay eso. La mayoría de los jóvenes están subordinados al capitalismo, a la globalización y la modernidad. Los jóvenes no lo asumen como tal. Sigue habiendo machismo, individualismo. Aquello vinculado a que los cargos tienen que ser rotatorios, que todos tienen que tener las mismas oportunidades, pero eso no es así. A mi parecer quisiera que fuera real, pero no lo es. La tarea de los jóvenes seria construir eso, reforzar esos conceptos, volverlos una práctica.

-Entonces, iqué es lo que diferenciaría a los jóvenes aymaras de un joven que no es aymara? ¿O sólo es la autoidentificación y el autoreconocimiento?

-Creo que no hay diferencia, para mí no hay diferencia entre quién se cree de una nacionalidad y quién no. Creo que los dos son iguales, tienen las mismas potencialidades, pero sí hay diferencia entre quien se asume y quien no se asume; se respeta también, pero yo no me veo ni menos ni más. Creo que lo único que nos separaría es no ser bolivianos, pero sí nos une el ser bolivianos y sí hay jóvenes que quieren construir un país que proporcione todas las necesidades que tenemos como jóvenes. En la democracia, tenemos que ir por este camino porque todos tenemos diversas formas de ver la vida y las cosas. Y es bien complejo todo lo que está pasando. En otros países hay más nacionalidades y se unen, ¿cómo aquí no podemos encontrar la unidad?

-De alguna manera iser aymara o el autoadscribirte como aymara te ha dado algunos beneficios? En tu juventud, algunas oportunidades que has tenido, ilas has obtenido por ser aymara?

- No, porque para mí es un tema personal. Cuando me preguntan yo les digo, pero luego, en mi vida cotidiana, yo considero que no debo recibir ningún beneficio, pero tampoco recibir ninguna discriminación. Aunque, claro, en cuestión de becas he participado en muchos encuentros internacionales, donde el mismo partido el MAS y las organizaciones de mujeres me han delegado. Tengo la posición política y, cuando te dan confianza, te dicen "andá". Yo creo que es el beneficio de que te autoidentifiques.

- iPodían delegar a otras? ¿Qué diferencia entre una u otra? ¿Quése valora?

- Sí se valora la persona que pueda desarrollar algunas ideas. Me han tocado dos personas que apostaban por los jóvenes. Me dieron la opción porque era joven. "Tú eres joven, tú puedes, anda". He hecho cursos en México, en Guatemala, en Santa Cruz, con el Fondo Indígena Internacional. Me recibieron por mi autoadscripción porque me he identificado como aymara.

- ¿Q̣é sería ser joven indígena hoy en día?

-Es complejo, te pierdes con toda la modernidad que te consume tanto, y por eso muchas veces olvidas eso y te subsumes en todo lo que va corriendo, especialmente cuando vives en la ciudad. Y creo que es más fácil insertarse en este movimiento de la 
ciudad cuando vienes del campo. Los chicos de manera inmediata encajan, claro, en grupos que los asumen como propios porque no en todos los grupos se encaja. Se encaja fácilmente cuando llegan a la ciudad.

-iPese a que hay leyes antirracistas existe el racismo?

- Yo creo que sí. He visto mucho racismo. En Sucre, cuando estaba en la Asamblea Constituyente, yo andaba con mi bolsita típica de aguayo y me decían "tienes que ocultar eso porque van a venir y te van a pegar". Entonces en Tarija les decían a los campesinos "hediondos y cochinos" y por qué no se iban a su ciudad. El dueño del hotel donde yo estaba me hablaba y yo veía mucho desprecio y racismo, y eso se ve más en ciudades pequeñas como Sucre o Tarija. El racismo contra indígenas era muy fuerte. No sabía cómo se expresaban así.

-Tú que hasestado en la Asamblea Constituyente, icómo valorarías lo plurinacional?

-Sí, veo muchas contradicciones. A partir de la nueva Constitución Política del Estado se ha tenido mucha esperanza, pero también ha habido muchas contradicciones; pero no es parte de la constitución, sino del sujeto. Es porque nosotros nos constituimos todavía en sociedad colonial, todavía racista, todavía discriminadora. Pienso que no son las leyes, sino son los ciudadanos los que tienen esos conceptos.

-Sianteshabíaunanaciónyahoraexisteloplurinacional, lo indígena, la identidad indígena iestá dada como prioritaria? ¿O cómo se entiende la identidad en un contexto de plurinacionalidad?

- Se ha manejado mal el concepto, porque decir soy tacana o soy aymara implica decir soy el relegado, el olvidado. Y no es una identidad que te pueda traer desarrollo y te sientas orgulloso, sino que somos los más pobres, los olvidados. Es un tema de identidad, pero no de oportunidades, y ahí noto una contradicción en el Estado plurinacional que se quiere tener.

- ¿Cómo o cuál es el Estado plurinacional que se quiere tener?
-Creo que el Estado plurinacional, para mí, es la diversidad de todas las nacionalidades. El concepto de "vivir bien" es importante, pero no soy fanática, por ejemplo, de la ideología verde, eso de la preservación del TIPNIS [Territorio Indígena Parque Nacional Isiboro Sécure]. Creo que las nacionalidades, lo identitario, tiene que estar involucrado, o asumir lo bueno de la modernidad porque, si no, te vas a seguir relegando como país, como nación o como pueblo. Hay muchos fundamentalistas verdes en este país, como hay muchos fundamentalistas de derecha que no permiten que sus pueblos se desarrollen.

-Y vuelvo a la pregunta, con todos los elementos que me relatas de cómo los jóvenes aymaras viven su identidad, ¿quées ser indígena hoy en día?

-Creo que es un todo, el hecho de que te vistas no te hace más o menos aymara, y el hecho de que hables aymara tampoco. Son todos los elementos. Eso que se dice es un todo integral. Es un reto porque la modernidad te absorbe, pero también tus raíces y lo espiritual te atrae. Lo del 24 de enero, lo de las alasitas o lo de San Juan te atrae, por más que vistas con tacos o lleves tu Ipad. La Ch'alla o el Gran Poder son fiestas en las que se mezclan lo espiritual y lo no espiritual. No es sólo folklore, pero te vincula. Hay gente que invierte en ello toda su plata. Ahí se juega el prestigio, porque están demostrando que tienen y que pueden también, aunque tengan que pagar todo el año el crédito que prestaron del banco.

-iA tus hijos les vas a transmitir la cultura aymara?

-Ellos yo creo que van a decidir qué asumir en su vida. Les daré a conocer la identidad aymara para él elijan lo que quieran ser. No me gustaría imponerles algo con lo que no se autoadscriben, pero sí que elijan, que vean.

-Tus sueños, Mireya, ¿cuáles son?

- Ser defensor del pueblo. Me gusta el área y quiero ser docente. Yo creo que cuando una persona tiene mucho que decir, puede hacer muchas cosas con los jóvenes y llegar a ellos. 
Finalizo destacando algunos aspectos que el relato de la joven aymara nos muestra: en primer lugar que, en el contexto político que se vive en Bolivia, y que es insoslayable, con el reconocimiento como Estado plurinacional y de las nacionalidades existentes en el país, los jóvenes se mueven en el ámbito movedizo de la identidad, manejando muy bien ambos espacios: el de su comunidad y el de la ciudad; en segundo lugar, que a pesar de los elementos simbólicos identitarios implicados en la construcción del Estado plurinacional, los jóvenes indagan sobre la posibilidad de construir una identidad común nacional, más allá de la diversidad. Con sus palabras, Mireya nos ha relatado un pequeño ejemplo de lo escurridiza que es la identidad, que en los jóvenes adquiere un carácter mucho más dúctil.

\section{La historia de una universitaria acateka}

Verónica Ruiz-Lagier
María Andrés-Francisco

\section{Introducción}

Este breve ensayo es un trabajo colaborativo realizado por Verónica Ruiz, antropóloga adscrita a la Dirección de Etnología y Antropología Social del Instituto Nacional de Antropología e Historia de México (DEASINAH), y María Andrés Francisco (Malín Antol Palás), normalista de 24 años, originaria de la comunidad acateka La Gloria, Chiapas, un ex campamento de refugio guatemalteco ubicado en el municipio de La Trinitaria

La población que hoy conforma La Gloria partió de Guatemala a finales de 1980 huyendo de la política militar de aquel país, conocida como tierra arrasada, que condujo a que se trasladaran a México más de doscientos mil refugiados. Quienes forman parte de la comunidad recorrieron varios campamentos de refugio antes de fundar su comunidad: Las Hamacas y El Chupadero, a dos y cuatro kilómetros respectivamente de la frontera, La Sombra y Las Chiripas, a un kilómetro de la línea fronteriza, y posteriormente Las Delicias, aproximadamente a cinco kilómetros de la línea fronteriza. $^{8}$

El 31 de enero 1981 ingresó el ejército guatemalteco al campamento Las Hamacas y atacó a la población. Atemorizados, los sobrevivientes partieron esa misma tarde hacia El Chupadero, donde se reunieron cerca de cinco mil personas. El 30 de abril de 1984 los refugiados de El Chupadero, que habían recibido a gente de La Sombra y Las Chiripas, sufrieron la segunda masacre a manos del ejército guatemalteco dentro de territorio mexicano. Con la intención de encontrar mayor seguridad, la gente realizó un nuevo desplazamiento, ahora hacia la colonia Las Delicias. Ante las condiciones de inseguridad, el Gobierno mexicano intentó trasladar a toda la población refugiada en Chiapas a los estados de Campeche y Quintana Roo, pero la mayoría se negó a alejarse más de Guatemala.

En la noche del 4 de junio de 1984, las personas asentadas en el campamento de refugiados de Las Delicias partieron hacia un terreno adquirido con ayuda de la diócesis de San Cristóbal. Lo realizaron en secreto para que las autoridades mexicanas no intentaran impedirlo y no los obligaran a trasladarse a otro estado; así que, desde la madrugada, y durante catorce horas, caminaron llevando con ellos a los enfermos, ancianos y a 1050 niños nacidos ya en territorio mexicano. Así nació La Gloria. Esta comunidad fue una de las primeras que decidió establecerse definitivamente en Chiapas, defender sus derechos como refugiados y, posteriormente, naturalizarse como mexicanos. Hoy es, sin duda, una de las comunidades indígenas más organizadas del municipio, de donde han salido los primeros licenciados por la Universidad Chapingo, las primeras parteras profesionales, las primeras normalistas acatekas de origen guatemalteco. Es una comunidad rectora con un acelerado proceso de cambio cultural que responde a varios factores de los que mencionaremos sólo dos: 1) Las dinámicas de discriminación que enfrentó la población al refugiarse en México, reproducidas ya fuera por la población o por las instituciones que atendieron a los refugiados, $y$ 2) el alto nivel de migración a Estados Unidos y zonas turísticas de México, con lo que buscan en la actualidad 
compensar las condiciones marginales en que quedaron insertos en el estado de Chiapas.

En este contexto nació y creció María Andrés Francisco, con la que he preparado la siguiente narración sobre su trayectoria personal, para reflexionar sobre el proceso de cambio cultural en su comunidad. Esto implica un ir y venir entre lo cotidiano y lo que resulta relevante cuando es comparado con la realidad del otro. En ese sentido, María ha vivido inmersa en la alteridad étnica mucho más que la mayoría de jóvenes de su edad. Ha cruzado varias fronteras simbólicas y culturales, y eso le permite mirar con otro lente su propia trayectoria de vida y planificarla de manera distinta a como lo hicieron otras mujeres de su familia.

La vida de María nos ayuda a entender qué elementos son más maleables en el grupo cultural al que ella pertenece, y qué otros han cambiado reciente y rápidamente como una convención surgida a partir de la realidad del refugio en México - derechos de la mujer, educación, noviazgo, etcétera-. Estos aspectos son dignos de considerar cuando se habla de juventud indígena y de cambio cultural.

Por otro lado, es importante integrar en cualquier reflexión las miradas etic y emic, para que no se imponga la visión del investigador. Al respecto, en este texto es únicamente la voz de Mary la que se refleja en el cuerpo central, y la tarea de la autora consistió en ordenar la información para presentarla al lector y realizar una reflexión final. El texto de Mary contiene información recabada en tres entrevistas que realizadas entre 2012 y 2013, dos en directo y dos más a través de internet, al que la comunidad ya tiene acceso desde inicios del año en curso.

\section{Entre la vida universitaria y la comunidad}

Tengo 24 años y nací en la comunidad de La Gloria. Cuando era niña pensaba que en Chiapas sólo se hablaba una lengua: el acateko, y que las demás personas hablaban castilla porque "eran mexicanos", como comúnmente se les dice o reconoce en mi comunidad.
Las cosas han cambiado en la comunidad. Cuando era chica no se acostumbraba que las mujeres salieran a estudiar o trabajar, pero todos los padres de familia veían bien que sus hijas estudiaran, porque de alguna manera tenían el conocimiento de que la educación era una forma de salir adelante. Luego, hace unos años, llegó a la comunidad el programa del INEA, en el cual se inscribieron en su mayoría mujeres, y las clases se impartían los fines de semana.

No se veía que las mujeres salieran solas a trabajar. Comúnmente se iban con sus esposos a trabajar en fincas o cafetales; y después, cuando los hombres comenzaron a migrar a Estados Unidos, las mujeres se han quedado en sus hogares como amas de casa, aunque algunas sí comienzan a migrar. Últimamente, las muchachas se van a trabajar en algunos estados de la República y los padres les dan permiso, pero creo que lo hacen sobre todo porque ya tienen más nivel educativo, eso les permite irse y ocupar un puesto mejor, en especial en el sector hotelero.

Yo no creo que por salir a estudiar o trabajar fuera de la comunidad nos estemos ladinizando, sólo salimos a aprender, a comunicarnos bien con el español. Las muchachas siempre regresan a su pueblo con sus esposos, pero no dejan en el olvido sus raíces y costumbres. Nunca he escuchado que hablen mal de las mujeres que salen a estudiar o trabajar; de hecho, se sabe que los de La Gloria sí se van a estudiar a otros lados y aprenden a hablar el español para comunicarse con otros.

En mi caso, mis papás nunca me prohibieron salir a trabajar o estudiar; nunca me dijeron "las mujeres deben estar sólo en su casa”, más bien estaban muy de acuerdo en que sus hijos estudiaran. Actualmente, gracias a Dios y con la ayuda de mis padres terminé la licenciatura en Educación Primaria Intercultural Bilingüe en la Escuela Normal Indígena Intercultural Bilingüe Jacinto Canek, ubicada en el municipio de Zinacantán, Chiapas. Tengo otras hermanitas que están en la prepa y una en la secundaria, pero yo soy la única de mi familia que ha estudiado una carrera. Mi hermana que está en la prepa dice que va a seguir estudiando, pero veremos, por la economía. Es un gasto muy fuerte. 
Yo tengo en el norte otra hermana y un hermano, pero mi hermana es la que se comprometió a ayudarme, por eso entré en la escuela, y como mi mamá veía que no alcanzaba, a veces le pedía ayuda a mi hermano, y sí, me ayudaba porque la Normal nos da una beca que sólo es de setecientos pesos mensuales.

Pocos en la comunidad hemos podido salir a estudiar una carrera. Algunos lo han logrado gracias a la beca que da la SEPI [Secretaría de Pueblos Indios], si no no se puede con los gastos, pero dan muy poquitas becas. Sinceramente, algunas compañeras del COBACH ya no siguieron estudiando por el problema del dinero, no porque se lo prohibiera su familia. Algunos de mis compañeros — que tampoco pudieron continuar estudiando- decidieron irse a trabajar a otros estados porque ya habían terminado la preparatoria.

¿Que cómo ingresé a la universidad? Al terminar mis estudios en el COBACH de La Gloria saqué mi ficha en esta Normal; desafortunadamente no aprobé $y$, al enterarme de la noticia, me fui a trabajar unos cuantos meses a Playa del Carmen, en Quintana Roo, con la única intención de ahorrar y sacar dos fichas al año siguiente. Fue entonces como sí me quedé en la Normal.

Ahí tuve una relación hermosa con un kaqchikel, porque en esta institución no se hace presente la discriminación, al contrario. Mis papás supieron que tenía novio pero no hubo problema, porque ahora ya se ve normal en la comunidad que las muchachas tengan novio. A mí me dejaron tener novio desde los 16 años. Ahora no tengo pero no me preocupa. Yo no tendría problema en hacerme novia de un chico de la comunidad que no haya estudiado una licenciatura, porque los hombres aunque no hayan estudiado pueden buscar una fuente de trabajo. Pero si mi novio me pidiera que dejara mi trabajo, no aceptaría. No le permitiría que me condicionara para casarnos.

Las mujeres ya no somos como antes, tenemos más derechos, y si estudiamos sabemos más sobre ellos. Todavía es difícil que en la comunidad la mujer tenga los mismos derechos que un hombre. Por ejemplo, es difícil que una mujer sea elegida como agente municipal o comisariado ejidal, de hecho, sólo han sido nombradas como tesoreras y otros cargos menores. Pero imagino que algún día los hombres tendrán que aceptar que tenemos derecho a ser nombradas autoridades, pues existen mujeres capaces de desempeñar esos cargos. Por ahora, las mujeres sólo se animan a trabajar en la oficina ejidal si son sólo mujeres las que están trabajando en el lugar o si son pocos los hombres.

Sin embargo, creo que mi comunidad no es muy diferente a otras de la región. Frente a otras acatekas, como El Colorado, la diferencia es que en ellas están dejando de usar su lengua, ya no se la enseñan a sus hijos; en cambio, en mi comunidad sí estamos orgullosos de nuestra cultura aunque lo demostremos únicamente en la fiesta de San Miguel con la coronación de la Reina Migueleña. Y creo que lo mismo está pasando en otras comunidades chiapanecas; ya no mantienen viva su cultura. Pero si me preguntas qué diferencias veo entre La Gloria y otras comunidades indígenas de Chiapas, te diría que la principal es el orgullo que tenemos por nuestra cultura. Y otra diferencia importante entre La Gloria y otras comunidades acatekas de la región es el tamaño del terreno en el que se construyó la comunidad y el acceso a la educación, pero principalmente que nosotros sí seguimos hablando nuestra lengua; por ejemplo, en Nueva Libertad ya no la enseñan a sus hijos, quizá porque les da pena. En cuanto a las diferencias con las comunidades de mexicanos [ladinas], creo que son pocas, por ejemplo: nosotros hablamos acateko, el número de profesionistas que tienen, la infraestructura de educación y la ubicación, o la religión.

Cuando entré a la Normal entendí que no somos tan diferentes los acatekos de otros pueblos de Chiapas. Al presentarme a mis compañeros y decir que soy hablante de acateko me preguntaban, “ide dónde eres?” Y me decían que nunca habían escuchado hablar de mi lengua. Me fui integrando paulatinamente con ellos, porque casi todos eran tseltales, tsotsiles, un mam, un zoque, un chol y yo, acateka, en fin, en el salón existía diversidad 
cultural y lingüística. La Normal nos hacía sentir más orgullosos de nuestra lengua y cultura, quizá porque todos los docentes pertenecían a otras culturas y nos hacían investigar sobre nuestra propia cultura, como sobre las fiestas tradicionales y las diferentes cosmovisiones. También nos fortalecían en cuanto a la escritura de nuestras lenguas, por eso pienso que esta escuela sí ayuda a reafirmar las raíces y la propia identidad de los pueblos indígenas porque se busca la formación de maestros interculturales y bilingües.

En cambio, mi formación en la primaria, en la telesecundaria y en el $\mathrm{COBACH}$, sinceramente fue muy distinta. En los primeros años de primaria el promotor de educación de la comunidad me daba clases en acateko. Entendía mejor lo que se me enseñaba porque me hablaban en mi lengua en comparación de los maestros oficiales con los que aprendí después, pero nadie decía nada de la importancia de mi lengua. En la telesecundaria se enseñaba inglés y otras asignaturas, y una maestra decía que nos comunicáramos en español, porque unos compañeros decían chistes en acateko y, como nos reíamos, la maestra lo consideraba una burla. Me acuerdo de que en ese entonces no sabíamos comunicarnos bien en español.

En el COBACH había dos grupos. Muchos compañeros se fueron dando de baja porque emigraban a Estados Unidos, y al final quedamos 23 en un solo grupo. Jamás se consideraron la lengua o la cultura como parte importante de los contenidos escolares, como actualmente lo hacen los docentes en la Normal.

En el COBACH estudié con mi hermana mayor y una amiga, María Elena. Al igual que ahora, tuve novios, uno hablante del español, un mestizo de la misma comunidad, y otro acateko, aunque actualmente no he tenido comunicación con ellos. En los primeros meses en la escuela "Jacinto Canek" yo visitaba a mi amiga, pero ella se fue a trabajar en otros estados de la República y la amistad se fue terminando. En ocasiones me encuentro con ex compañeras del COBACH y les hablo, pero ya no es como antes, la confianza termina. $\mathrm{Y}$ algunas amigas ya están casadas y con hijos, y no se da el caso de que se pongan a platicar en medio camino.

Sólo somos tres las mujeres que salimos a estudiar a la Normal, dos en la Jacinto Canek y una en la UPN, más las cuatro chicas que han estudiado en la Escuela Profesional de Partería en San Miguel de Allende con beca de una ONG suiza, y algunas más que han estudiado fuera con apoyo de su familia. Pero lo que sí es verdad es que ya somos tres maestras acatekas.

Creo que la escuela Jacinto Canek es la única que valora nuestra cultura. Al llegar nos sentimos muy aceptados, nos preguntan sobre nuestra lengua y se siente uno muy bien. Diseñamos materiales didácticos para enseñar nuestra propia lengua, como por ejemplo juegos de lotería, con las 36 grafías del acateko en tarjetas con dibujos, memoramas o un juego que se llama "traga letras". Con esos juegos hacemos dinámicas en las clases y los niños van aprendiendo.

Para titularme elegí como tema "la fiesta de San Miguel Arcángel, punto nodal para la enseñanza de la lectoescritura del acateko con alumnos de $4^{\circ}$ grado de primaria bilingüe", porque es la fiesta más grande que conocen los alumnos de la comunidad. Yo estoy haciendo mi servicio social en mi comunidad, y así voy relacionando la fiesta patronal con las asignaturas. El punto nodal es una metodología de enseñanza que permite al docente elaborar su planeación didáctica de manera interdisciplinaria, planeando con diversas asignaturas contextualizadas, de modo que los alumnos construyen sus conocimientos a partir de un saber comunitario que involucra su contexto sociocultural y se consideran los conocimientos previos del educando para lograr un aprendizaje significativo. Enseñar la lengua escrita acateka implica motivar al alumno a que hable y escuche con respeto a otras personas al comunicarse en acateko. Asimismo, enseñar la gramática de este idioma y sus características a partir de la fiesta de San Miguel Arcángel consiste en articular diversas asignaturas vigentes en la educación básica, por ejemplo: matemáticas/elección de la reina acateka, español/ recetarios de cocina, historia/estudio sobre la cultura 
maya en general, y lengua indígena/sopa de letras con los nombres de los animales de la danza de la conquista. También se plantea que para la enseñanza de la lengua escrita acateka se usen los parámetros curriculares de la lengua indígena.

A mí me gusta mucho mi carrera, me gusta mucho. A parte de lo académico, es muy divertido para mí, y el cariño de los niños... a veces te llegan a querer de verdad. Se siente bonito.

Antes los papás no querían que se les enseñara a los niños en lengua, sino en español solamente. De hecho, antes llegó una maestra kanjobal a La Gloria y, como se parece el kanjobal al acateko, la maestra hablaba su lengua y por eso la corrieron. Eso fue como en 2004. Se llama Juana Pascual. Le dijeron que los alumnos no aprendían el español. No les interesaba que los niños entendieran los contenidos, sino que aprendieran el español. Yo creo que, si se les explica en lengua, entienden más, porque sólo hasta el 5 to y 6to de primaria dominan más el español y, mientras tanto, la asignatura que más les cuesta trabajo es matemáticas porque entienden las palabras en español, pero no el sentido de la oración.

También les cuesta la geografía por los mapas, pero el problema es que los profesores no relacionamos la geografía con la comunidad y la cultura. Nunca les hemos enseñado con mapas de dónde vienen nuestros padres y abuelos, dónde están las aldeas en las que ellos nacieron o dónde se ubican los pueblos acatekos de Guatemala. Algunos padres de familia les dicen a veces "mi papá está enterrado en tal lugar, vivíamos en tal lado"; solamente así pueden aprender, y ya queda en el niño si lo memoriza o no.

En cambio, cuando estudié en la Normal sí aplicaba los conocimientos acatekos. Pedían muchos trabajos sobre las cosmovisiones, sobre la forma que tiene uno de considerar y ver las cosas: el diablo, los rayos, el árbol que tiene vida, el maíz, el agua, todo tiene un significado; y de la fiesta, de mi traje que me puse bastantes veces para eventos de la universidad y para la escolta de la Normal. Hubo un foro de Filosofía Indígena y, como era la comandante de la escolta, lo dirigía en lengua, y como mis compañeros no hablaban mi lengua, tuvieron que aprender lo que yo decía. Eso me gustó mucho.

Antes de ir a la Normal no sabía cómo se llamaba a nuestras costumbres y nuestra forma de ver el mundo, sólo sabía que existían y ya. Muchos de esos conocimientos los sabía y otros los investigué con Méndez, el catequista comunitario, porque fui del grupo juvenil de la Iglesia en la comunidad y él me conocía bien. Él me ayudó.

No sé si las compañeras que no salieron a estudiar valoren igual que yo nuestra cultura, quizá no saben de su importancia ni le llamen cosmovisión, pero saben de esas costumbres. Algunas costumbres ya las hemos dejado. Ya no le rezan al cerro como lo hacían los de la "costumbre", pero conocen qué significa. Igual, mi mamá me comenta que antes se le rezaba al cerro para que lloviera, pero ahora ya no. En 2006 murió elúltimo viejito rezador y quedó su compañero, que ya es muy grande. Sí, ellos dos siempre rezaban en el registro de agua el día 3 de mayo como hacían los de la "costumbre", pero en el pozo, ya no en el cerro como antes.

No sé por qué no se ven estos temas en la escuela de la comunidad. Quizá porque los maestros oficiales son de otros lados y, aunque la escuela es bilingüe, envían maestros que hablan otras lenguas. Y es que en el sistema educativo del estado se reciben muchos maestros indígenas que los mandan a trabajar en contextos diferentes a los de ellos, lo cual implica aprender la lengua y considerar los conocimientos culturales de los alumnos, pero no lo hacen. Creo que con el tiempo el concepto de interculturalidad irá adquiriendo más significados porque todo parte del respeto mutuo, el respeto entre una cultura y otra y entre una persona y otra; debe respetarse la diferencia del otro, que puede crecer desde la diferencia propia. Entonces, la interculturalidad es un concepto que actualmente se requiere ver reflejado en el territorio mexicano, pero implica mucha conciencia y mucho trabajo por parte de todos, y no de unos cuantos.

Lasinstituciones educativas no ven las condiciones distintas en las escuelas y sus alumnos, por eso me sumé al movimiento magisterial ahora que me dieron 
mi plaza como maestra, porque no consideran la trayectoria escolar o laboral, y a veces no te integran al sistema bilingüe aunque lo seas pues dicen que no hay suficientes plazas; eso fue lo que me pasó a mí, no quisieron darme mi plaza como maestra bilingüe.

El año pasado fui a la Ciudad de México junto con los maestros democráticos de la CNTE; me fui sin el permiso del supervisor. Fue una experiencia muy importante. Hay cosas en las que no estoy de acuerdo con ellos, pero en otras sí, por ejemplo, estoy de acuerdo en que nos apliquen evaluaciones a los maestros, pues eso fue lo que hice al ingresar al magisterio, presenté mi examen nacional para la plaza. Pero no estoy de acuerdo en que nos despidan si reprobamos el examen, pues perderíamos la plaza y el gobierno se deslinda de darnos los derechos que ya teníamos, por ejemplo bonos y aguinaldos; y si el maestro quiere seguir trabajando, será sólo para cubrir interinatos. Lo más feo de esto es que sólo te llegan los resultados vía internet. Si reprobaste o no, nadie te explica en dónde o en qué aspecto saliste bien o en qué fallaste; por eso se entiende que desde instancias mayores pueden alterar los resultados.

Y, bueno, estos problemas nos preocupan a todos seamosindígenas o no. Yo, de hecho, no veo diferencias entre los maestros indígenas y los que no lo somos, aunque sólo podría comparar con los maestros que conocí durante mi servicio y los que he conocido en este primer ciclo escolar. Y somos iguales, la diferencia es sólo el centro de trabajo al que pertenecemos, es decir, si es modelo bilingüe o monolingüe. Y, bueno, lo que queremos es lo mejor para nuestras comunidades y poder trabajar haciendo lo que nos gusta. Yo, por ejemplo, me veo en diez años con una familia hermosa, con la bendición de Dios, y trabajando como maestra o como directora técnica. Ese es mi sueño.

\section{Conclusiones}

Como reflexión final me gustaría resaltar algunos aspectos que considero relevantes en la narración hecha a partir del testimonio de María, por ejemplo, aquello que tiene que ver con la discriminación, que no es un tema retomado por ella en su narración. Eso demuestra que partimos de miradas y experiencias distintas, y de ahí la necesidad de entretejer la visión emic y etic. Ella nació junto con su comunidad, cuando era pequeña recibió atención médica y educativa por parte de promotores comunitarios y en su propia lengua; nació en una comunidad bien organizada en la que se resolvían colectivamente las necesidades de adquisición de tierra, cultivo o infraestructura comunitaria. A ella no le tocó vivir la persecución de las autoridades de inmigración ni enfrentar los malos tratos de los funcionarios de gobierno. Por el contrario, bajo el cobijo comunitario, pero sabiendo que existían ellos y "los mexicanos", creía que sólo ellos eran indígenas e ignoraba que existían en su estado otros pueblos mayas.

La información que ella proporciona no permite al lector conocer las dinámicas de discriminación que sufrió la población refugiada, al igual que otros pueblos indígenas, en ciudades como Comitán o Tuxtla Gutiérrez. Mary recientemente ha comenzado a reflexionar sobre las razones por las que el sistema oficial de educación en el que estudió la secundaria y el bachillerato no integra un modelo intercultural ni los saberes locales de su comunidad. Su paso por la Normal Jacinto Canek le generó orgullo y respeto hacia su especificidad cultural, y de ahí parte ahora, como profesional, para relacionarse con sus alumnos en otras comunidades fronterizas.

Otro aspecto que considero relevante es la naturalidad con la que Mary ve el derecho que tienen las mujeres a la educación, a elegir la pareja, a trabajar fuera de casa, puesto que sólo una generación atrás las mujeres tuvieron que pelear este derecho en un contexto de por sí adverso, como es el refugio. Las organizaciones no gubernamentales y la diócesis de San Cristóbal trabajaron insistentemente en ese punto con talleres, hasta conseguir que ellas mismas se organizaran en grupos como el llamado Mamá Maquín, en el que las mujeres organizadas consiguieron alfabetizar a setecientas mujeres refugiadas en México. Si bien esa organización terminó su trabajo en México en 1993, cuando gran parte de la población refugiada retornó colectivamente a Guatemala, está claro que la experiencia comenzó a 
modificar algunos aspectos en la relación entre mujeres y hombres..$^{10}$ Puedo asegurar que esto no ha sido ni lineal ni generalizado, pero ese antecedente, junto con el de la experiencia migratoria, ha incidido lentamente en la representación social de la mujer dentro de la comunidad, y en específico entre los jóvenes. ${ }^{\text {II }}$

Por lo tanto, para estudiar el cambio cultural en las comunidades de refugio debemos tener presente el antecedente político de la comunidad, su posible participación en el movimiento revolucionario -que formó ideológicamente a hombres y mujeres-, su organización en el refugio, su movilización para adquirir derechos ciudadanos como naturalizados y la incidencia de los "norteños" o migrantes que retornan con nuevos valores. En todo caso, cuando de cambio cultural se trata lo relevante es entender qué prácticas y elementos culturales son los que los jóvenes reivindican y cuáles no consideran necesarios para seguir siendo parte de su comunidad y de su grupo cultural. Mary, y quienes como ella partieron para formarse profesionalmente, continúan haciendo uso de su lengua y se reivindican como jóvenes acatekas con deseos de trabajar, de ayudar a su familia económicamente, de tener una pareja que las respete y valore. No son como fueron sus abuelas. Escogen a la pareja, usan pantalones y no el "corte" tradicional, se cortaron el pelo y trabajan temporalmente fuera de su comunidad. Ganan dinero en ciudades turísticas y hasta cruzan el desierto como migrantes a Estados Unidos, aprenden otros idiomas y adquieren nuevos estilos en su hablar acateko y en el español, quieren conocer otros lugares pero les gustaría también regresar a la comunidad a fortalecer el sistema educativo, a retribuir a la familia y a su pueblo por lo que ellas recibieron, y eso es parte también del "hacer comunidad".

\section{Notas}

${ }^{1}$ Centro de Multiservicios Educativos CEMSE “[...] una obra de la Compañía de Jesús en Bolivia, trabajamos desde 1985 al servicio de la educación boliviana, con la finalidad de promover la igualdad de oportunidades en educación y salud', en especial, de las poblaciones excluidas o en desventaja social" (ver: http://www. cemse.org.bo/webcemse/index.php/que-es-el-cemse/ acerca-del-cemse?view=default).

${ }^{2}$ Traje formal de dos piezas que consiste en un pantalón y saco de tela.

${ }^{3}$ Madre tierra a la que se respeta y venera.

${ }^{4}$ Ch'allar, rito para bendecir con la finalidad de que las cosas salgan bien.

${ }^{5}$ Milluchada, rito con sahumerio que se hace para que cualquier reunión u otra actividad se desarrolle con éxito.

${ }^{6}$ Zapatos típicos hechos de cuero o de goma.

${ }^{7}$ Constitución Política del Estado.

${ }^{8}$ Ver esquema sobre rutas de los campamentos de refugio al final del artículo. Para saber más sobre el proceso de refugio ver: Verónica Andrés (2002). En búsqueda de la comunidad. El caso de La Gloria, Chiapas, tesis de maestría, CIESAS, México.

${ }^{9}$ Instituto Nacional para la Educación de los Adultos

${ }^{10}$ Mamá Maquín (2009). Nuestra experiencia ante los retos del futuro. Sistematización del trabajo de las mujeres de Mamá Maquín durante el refugio en México y su retorno a Guatemala. Chiapas: ACNUR/Mamá Maquín.

${ }^{11}$ El cambio del papel de la mujer como representación social lo he trabajado anteriormente. Ver: Verónica Andrés (en prensa). Ser mexicano en Chiapas. Identidad y ciudadanización entre los refugiados guatemaltecos en el municipio de La Trinitaria. México: INAH. 
Mapa 1. Rutas del refugio hacia México

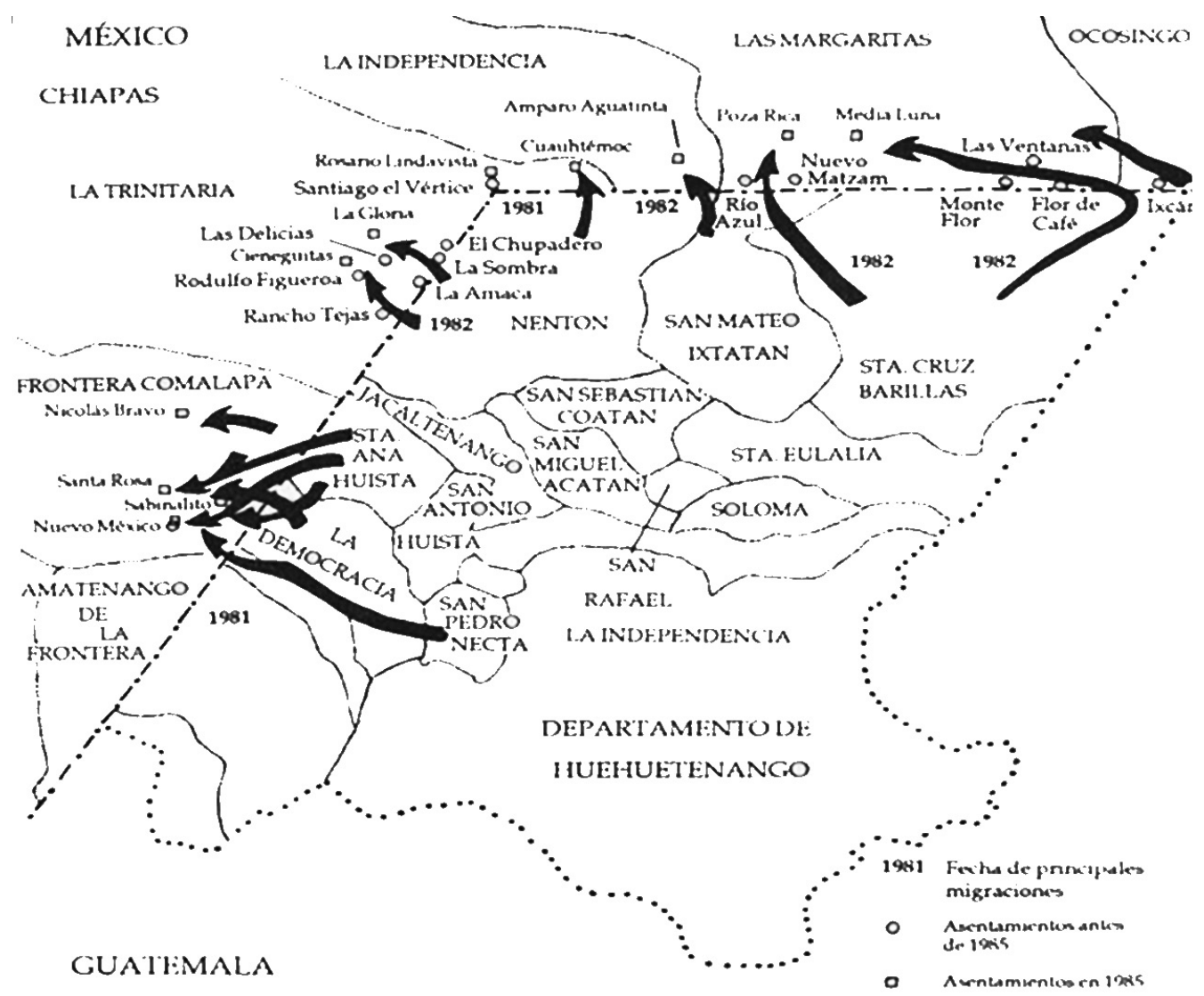

Fuente: Sergio Aguayo, 1987. 